\title{
FORMULATION AND STABILITY EVALUATION OF ATENOLOL GEL IN TWO DIFFERENT BASES
}

\author{
ANIS YOHANA CHAERUNISAA*, SORAYA RATNAWULAN MITA, DEWI DAILAH RAHMAT
}

Pharmaceutical Technology Laboratory, Faculty of Pharmacy, Universitas Padjadjaran, Jl Raya Jatinangor Km 21.5 Sumedang, 45363, Indonesia. Email: anis.yohana.chaerunisaa@unpad.ac.id

Received: 12 November 2018, Revised and Accepted: 04 January 2019

ABSTRACT

Objective: The aim of the research about atenolol gel is to formulate and evaluate its stability in hydroxypropyl methylcellulose (HPMC) and Aqupec HV-505 gel base.

Methods: Gels were formulated using Acupev HV-505 and HPMC at three different concentrations. Physicochemical evaluation and stability testing were performed including organoleptic examination, $\mathrm{pH}$, viscosity, consistency, bleeding, qualitative analysis by thin-layer chromatography (TLC), and quantitative analysis by UV-visible spectrophotometry during 56 days of storage.

Results: Physicochemical evaluation showed that the best formula was the one with 1\% Aqupec HV-505 base (FA2). Further investigation was conducted by varying atenolol concentration to study the influence on gel stability. Evaluation on organoleptic performance, pH, viscosity, consistency, bleeding, microbiology, and qualitative and quantitative stability testing using TLC and UV-visible Spectrophotometry during 56 days of storage showed that the best gel formula was FA22, the one using $1 \%$ Aqupec HV-505 with $0.5 \%$ Atenolol The patch test showed that all atenolol gels were safe to be used.

Conclusions: About 1\% Aqupec HV-505 provided good physical properties and physicochemical stability to be used as gel base.

Keywords: Atenolol, Gel, Stability.

(C) 2019 The Authors. Published by Innovare Academic Sciences Pvt Ltd. This is an open access article under the CC BY license (http://creativecommons. org/licenses/by/4. 0/) DOI: http://dx.doi.org/10.22159/ajpcr.2019.v12i3.30727

\section{INTRODUCTION}

Atenolol is one of the $\beta$-selective adrenergic blocking agents in the treatment of angina pectoris. It is reported to have extensive hepatic first-pass effect after oral administration [1,2]. It is also very well known that conventional therapy such as orally, may result higher fluctuations in plasma concentration of the drug and unwanted side effect [3]. Hence, the transdermal drug delivery system that provides a predetermined constant drug delivery would be beneficial for effective and safe therapy [4]. Most of the transdermal delivery is formulated as topical preparations. The main advantage of this system is to overcome the first-pass metabolism. Other advantages of topical preparations are avoidance of the risks and inconveniences of intravenous therapy and reducing the effect of varied conditions on drug absorption, like $\mathrm{pH}$ changes, presence of enzymes, gastric emptying time are [5-7].

Gels, as semisolid base for transdermal preparation, are a class of dosage form which have a higher aqueous component that permits greater dissolution of drugs and also permits easy migration of the drug through a vehicle that is essentially a liquid, compared with the ointment or cream base [8-11]. Kim and Shin developed and studied the release of atenolol from the ethylene-vinyl acetate matrix containing various plasticizers. Many other study also developed increased release from topical formulation [12-15]. Hence, the objectives of this study were to formulate and investigate the physicochemical stability of atenolol in two different gel bases. The influence of gelling agent, drug loading effect, and skin irritation studies were also evaluated.

\section{MATERIALS AND METHODS}

Materials

Atenolol (PT Kalbe Farma), Ammonia 21\%, Aqupec HV-505 (Sumitomo Seika), Aquadest, DMDM hydantoin, Ethyl acetate, (hydroxypropyl methylcellulose [HPMC], Bratachem), Methanol (Bratachem), Nutrient
Agar (Oxoid), Propylene glycol (Bratachem), and Triethanolamine (TEA, Bratachem) were used.

Atenolol content was determined by Spectrophotometry UV-visible (Specord 200). The pH was measured by $\mathrm{pH}$-meter 744 Methrohm while gel viscosity was measured by Viscotester Rion (VT-04 F).

\section{Methods}

Preparation of gels

HPMC gels

The composition of gel formulation is shown in Table 1. The HPMC was dispersed with continuous stirring until uniformly dispersed and the solution was allowed to cool to $50^{\circ} \mathrm{C}$. The other ingredients were added with continuous stirring. Atenolol dissolved in propylene glycol was added slowly with stirring. Other ingredients were added slowly while stirring until homogenous gel was obtained.

\section{Aqupec HV-505 gels}

Aqupec HV-505 powder was dispersed in hot water and stirred with a stirrer at $2500 \mathrm{rpm}$, and the gels then were left overnight at ambient temperature. Triaethanol amine was added until the clear gel was obtained. Atenolol was dissolved in propylene glycol and was added slowly with stirring into solution; the other ingredients were added with continuous stirring.

Physical stability investigation

Parameters investigated including organoleptic and bleeding investigation, $\mathrm{pH}$, and viscosity measurement.

\section{Microbial investigation}

This study was conducted to investigate the efficacy of DMDM hydantoin as the preservative after the gels were stored for 14 days. The study was conducted by counting method. 
Table 1: Formula of atenolol gel

\begin{tabular}{|c|c|c|c|c|c|c|}
\hline \multirow[t]{2}{*}{ Ingredients } & \multicolumn{3}{|l|}{$\mathbf{F}_{\mathrm{A}}$} & \multicolumn{3}{|l|}{$\mathbf{F}_{\mathrm{B}}$} \\
\hline & $F_{\mathrm{A} 1}$ & $F_{A 2}$ & $\mathbf{F}_{\mathrm{A} 3}$ & $F_{B 1}$ & $F_{B 2}$ & $F_{\mathrm{B} 3}$ \\
\hline HPMC (\%) & - & - & - & 1.50 & 2.00 & 2.50 \\
\hline Aqupec HV-505 (\%) & 0.50 & 1.00 & 1.50 & - & - & - \\
\hline Atenolol (\%) & 0.50 & 0.50 & 0.50 & 0.50 & 0.50 & 0.50 \\
\hline TEA (\%) & 1.00 & 1.75 & 2.50 & 1.00 & 1.00 & 1.00 \\
\hline Propylene glycol (\%) & 25.00 & 25.00 & 25.00 & 25.00 & 25.00 & 25.00 \\
\hline Ethyl acetate (\%) & 5.00 & 5.00 & 5.00 & 5.00 & 5.00 & 5.00 \\
\hline DMDM hydantoin (\%) & 0.30 & 0.30 & 0.30 & 0.30 & 0.30 & 0.30 \\
\hline Aquadest ad (\%) & 100.00 & 100.00 & 100.00 & 100.00 & 100.00 & 100.00 \\
\hline \multicolumn{7}{|c|}{$\begin{array}{l}\mathrm{F}_{\mathrm{A}}: \text { Formula gel using Aqupec } \mathrm{HV}-505, \mathrm{~F}_{\mathrm{A} 1}: \text { Formula gel using Aqupec } \\
\mathrm{HV}-5050.5 \%, \mathrm{~F}_{\mathrm{A}}: \text { Formula gel using Aqupec HV-505 1\%, } \mathrm{F}_{\mathrm{A} 3}: \text { Formula gel } \\
\text { using Aqupec } \mathrm{HV}-5051.5 \%, \mathrm{~F}_{\mathrm{B}}: \text { Formula gel using HPMC, } \mathrm{F}_{\mathrm{B} 1} \text { : Formula gel using } \\
\text { HPMC } 1.5 \%, \mathrm{~F}_{\mathrm{B} 2}: \text { Formula gel using HPMC2\%, } \mathrm{F}_{\mathrm{B} 3}: \text { Formula gel using HPMC } 2.5 \text {. } \\
\text { TEA: Triethanolamine }\end{array}$} \\
\hline
\end{tabular}

Table 2: Formula of gel with various concentration of atenolol

\begin{tabular}{lllll}
\hline Ingredients & $\mathbf{F}_{\mathbf{A 2 . 0}}$ & $\mathbf{F}_{\mathbf{A 2 . 1}}$ & $\mathbf{F}_{\mathbf{A 2 . 2}}$ & $\mathbf{F}_{\mathbf{A 2 . 3}}$ \\
\hline Aqupec HV-505 1(\%) & 1.00 & 1.00 & 1.00 & 1.00 \\
Atenolol (\%) & - & 0.50 & 1.00 & 1.50 \\
TEA (\%) & 1.75 & 1.75 & 1.75 & 1.75 \\
Propylene glycol (\%) & 25.00 & 25.00 & 25.00 & 25.00 \\
Ethyl acetate (\%) & 5.00 & 5.00 & 5.00 & 5.00 \\
DMDM hydantoin (\%) & 0.30 & 0.30 & 0.30 & 0.30 \\
Aquadest ad (\%) & 100.00 & 100.00 & 100.00 & 100.00 \\
\hline
\end{tabular}

$\mathrm{F}_{\mathrm{A} 2.0}$ : Formula of Aqupec HV-505 1\% gel without atenolol, $\mathrm{F}_{\mathrm{A2} 2 \mathrm{1}}$ : Formula of Aqupec HV-505 1\% gel with atenolol 0.5\%, $\mathrm{F}_{\mathrm{A} 2.2}$ : Formula of Aqupec HV-505 1\% gel with atenolol 1.0\%, $\mathrm{F}_{\mathrm{A} 23}$ : Formula of Aqupec HV-505 1\% gel with atenolol 1.5\%. TEA: Triethanolamine

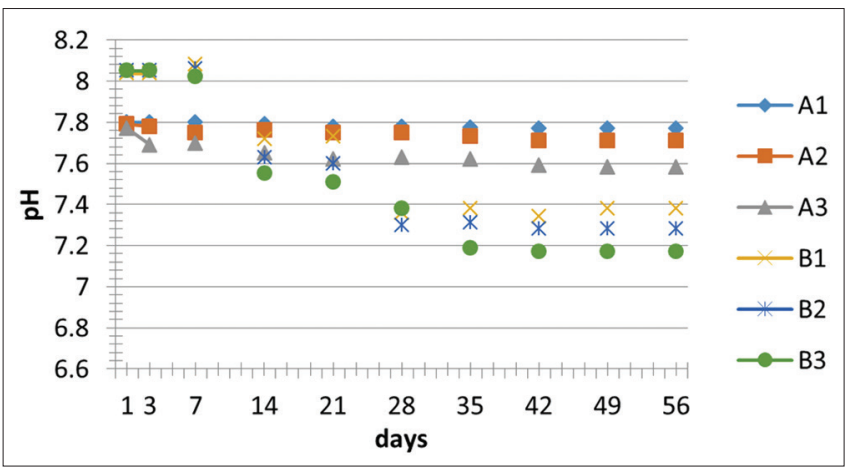

Fig. 1: pH of atenolol gels in various bases

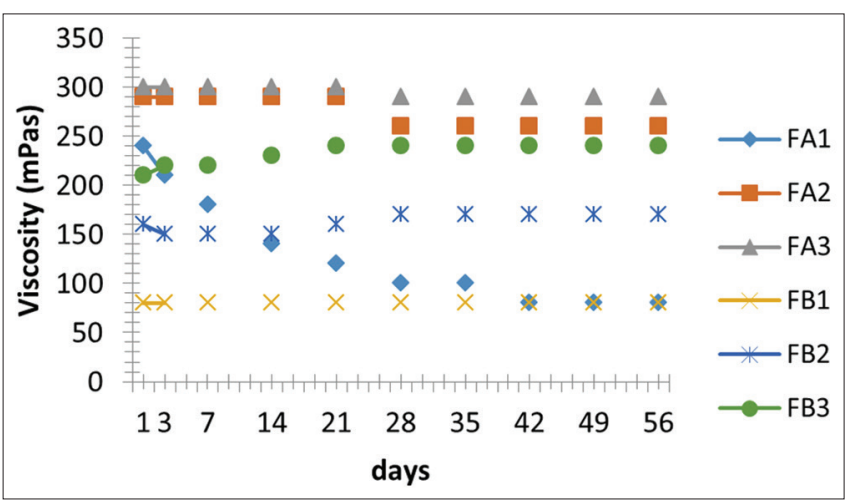

Fig. 2: The viscosity of each gel during the time of storage

Qualitative and quantitative determination of atenolol in gel Qualitative analysis was performed by thin-layer chromatography
(TLC) into gel. Samples were dissolved in methanol and the eluent was ammonia:methanol (1:4). The spot was observed at UV light $254 \mathrm{~nm}$.

Quantitative analysis was conducted by measuring the atenolol content in the sample. $1 \mathrm{~g}$ of gel was accurately weighed and placed in a $100 \mathrm{ml}$ volumetric flask containing $30 \mathrm{ml}$ of methanol, stirred for $30 \mathrm{~min}$, and made up to volume. The amount of atenolol was calculated using standard obtained curve. The determination was conducted at $1^{\text {st }}$ day and $56^{\text {th }}$ day of preparation.

\section{Safety test}

The safety test was conducted into 10 volunteers using patch test method.

\section{RESULTS AND DISCUSSION}

Physical stability investigation of atenolol in Aqupec HV-505 and HPMC bases

Organoleptic investigation showed that all formulae have smooth texture, odorless, and spreadable. Gel with HPMC base was white opaque, while the one with Aqupec HV-505 was clear and transparent. The result was stable during 56 days of storage. Based on aesthetic considerations, Aqupec HV-0505 1\% was best one for gel base. So it is used for next experiment to which variating the Atenolol concentration in gels.

\section{pH of gels in various bases}

Ideal $\mathrm{pH}$ for topical preparation is $5.5-10$. The result showed that $\mathrm{pH}$ of $F_{A}$ was 7.58-7.80, and it means that all gels with Aqupec HV-505 and HPMC base fulfilled the $\mathrm{pH}$ requirement. The $\mathrm{pH}$ was decreased during 56 days of storage, especially FB formulas, but they all still in required $\mathrm{pH}$ for topical preparation. $\mathrm{pH}$ of gels during storage is shown in Fig. 1.

\section{Viscosity of gels}

Investigation on gels' viscosity gave the results that viscosity was decreased during the time of storage (Fig. 2). A decrease in viscosity may due to indirectly monitor chemical degradation because changes at the molecular level may cause changes in viscosity [16-18].

Further investigation was conducted by varying the atenolol concentration on 1\% Aqupec HV 505. Based on organoleptic investigation, almost all gels were also clear, transparent, and well spreadable. Aqupec HV-505 1.5\% became turbid, especially, after 0.5\% atenolol was added. No bleeding happened in all gels during 56 days of storage. Formula used in gels with various concentration of atenolol is shown in Table 2.

Physical stability investigation of 1\% Aqupec HV-505 gels with various concentration of atenolol

Organoleptic investigation

Based on the result of organoleptic investigation including color, smell, and consistency during 56 days of storage, it was concluded that $\mathrm{F}_{\mathrm{A} 20}$ $\mathrm{F}_{\mathrm{A2.1}}, \mathrm{F}_{\mathrm{A} 2.2}$, and $\mathrm{F}_{\mathrm{A} 2.3}$ had homogenous and stable during the time of investigation at ambient temperature. The results show that there were no visible changes in the gel formulation.

\section{pH of gel}

The $\mathrm{pH}$ of $\mathrm{F}_{\mathrm{A} 2}$ was 7.74-8.30. Addition of atenolol causes an increase in $\mathrm{pH}$. It may be caused by the physicochemical of Atenolol itself as weak base. The increase in the concentration of atenolol resulted in bigger $\mathrm{pH}$ value of gels. The $\mathrm{pH}$ of gels with various concentration of atenolol is shown in Fig. 3.

\section{Viscosity of gels}

The viscosity of gels containing atenolol was lower compared with those without atenolol, which is due to internal and molecular change of atenolol addition. Furthermore, the results revealed that the increase of atenolol concentration in gel formulation did not affect the viscosity. Effect of time of storage was investigated for 56 days. The results 


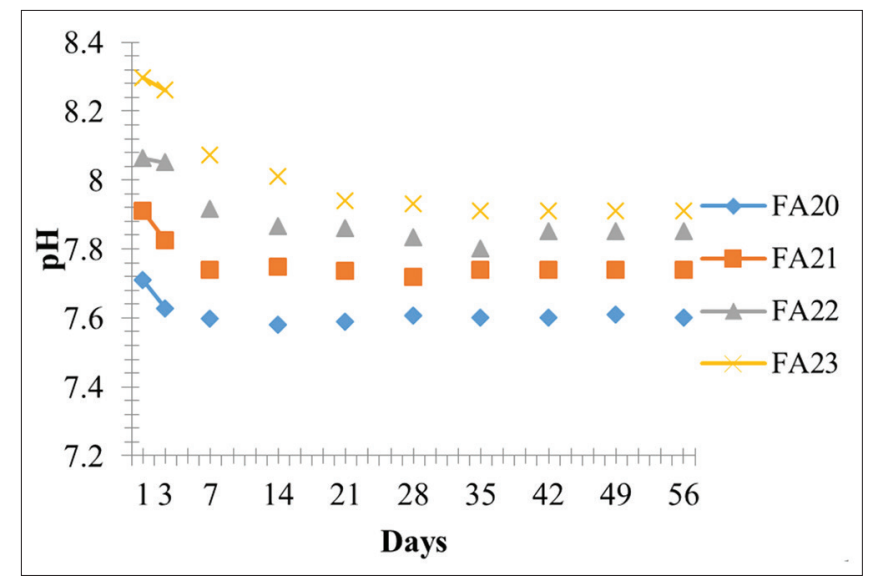

Fig. 3: pH of gels with various concentration of atenolol during the time of storage

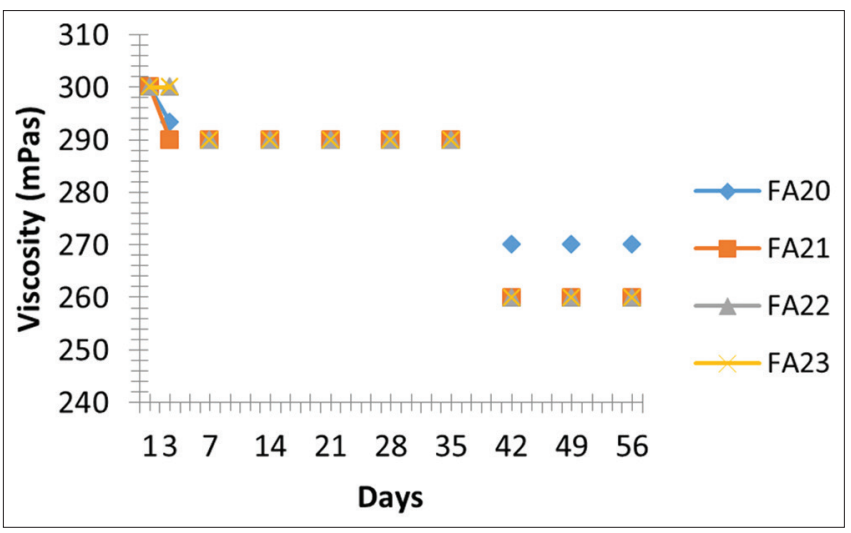

Fig. 4: Viscosity of gels with various concentration of atenolol during the time of storage

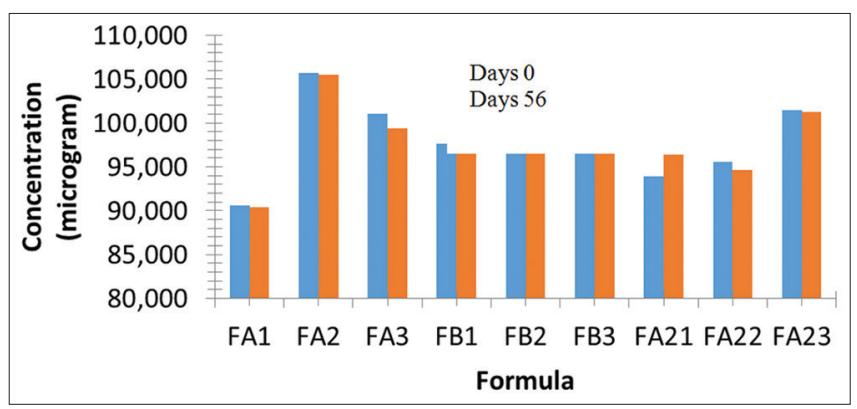

Fig. 5: Atenolol content in gels

Table 3: Qualtitative analysis of atenolol after formulation and 56 days of storage

\begin{tabular}{lll}
\hline Formula & $\mathbf{R}_{\mathbf{f}}$ days of $\mathbf{0}$ & $\mathbf{R}_{\mathbf{f}}$ days of $\mathbf{5 6}$ \\
\hline Atenolol powder & 0.8846 & 0.8923 \\
$\mathrm{~F}_{\mathrm{A} 1}$ & 0.8925 & 0.8923 \\
$\mathrm{~F}_{\mathrm{A} 2}$ & 0.8923 & 0.9000 \\
$\mathrm{~F}_{\mathrm{A} 3}$ & 0.9000 & 0.9000 \\
$\mathrm{~F}_{\mathrm{B} 1}$ & 0.8846 & 0.8846 \\
$\mathrm{~F}_{\mathrm{B} 2}$ & 0.8923 & 0.8923 \\
$\mathrm{~F}_{\mathrm{B} 3}$ & 0.8769 & 0.9000 \\
$\mathrm{~F}_{\mathrm{A} 2.1}$ & 0.8923 & 0.8846 \\
$\mathrm{~F}_{\mathrm{A} 2.2}$ & 0.8923 & 0.8923 \\
$\mathrm{~F}_{\mathrm{A} 2.3}$ & 0.9000 & 0.8923 \\
\hline
\end{tabular}

showed that gel formulation was stable after 56 days of storage. Viscosity of gels with various concentration of atenolol during the time of storage is shown in Fig. 4.

\section{Microbial Investigation}

The test was conducted to prove that preservative used in formulation was effective. It was found that there was no bacterial growth after 14 days of investigation which can be concluded that the preservative is effectively worked in the gels.

\section{Qualitative analysis by TLC}

The purpose of the study was to investigate atenolol content in gels during the time of storage. First, the investigation was conducted by qualitative analysis using TLC method. Furthermore, the quantitative analysis was conducted to investigate the homogeneity content of atenolol in gel preparation. The study was performed into all gels at the day of preparation and after 56 days of storage. Qualitative analysis by TLC method showed that $\mathrm{R}_{\mathrm{f}}$ of atenolol in gels and atenolol powder as standard were unchanged after formulation, as well as after 56 days of storage as shown in Table 3.

\section{Quantitative analysis}

Atenolol content in gels is shown in Fig. 5. From the results, it can be concluded that drug content in gels did not significantly changed during the time of storage. Stability of atenolol in gel formulation can be explained by inert matrix using as gel basis. HPMC and Carbopol as matrix used in gel basis revealed the stability for atenolol after 56 days of storage.

\section{Safety test}

Safety test was conducted by Patch test method to find out whether the formulation may be caused or aggravated by a contact allergy to the skin. Positive reactions were observed; skin reaction nearly becomes red and/or itchy. The safety test gave the result that all gels were save to be used because it did not give the allergic reaction to the volunteers.

\section{CONCLUSIONS}

Organoleptic investigation showed that all formulae have smooth texture, odorless, and spreadable. Gel with HPMC base was white opaque, while the one with Aqupec HV-505 were clear and transparent which was stable during 56 days of storage. Gels with Aqupec HV505 and HPMC base were fulfilled the $\mathrm{pH}$ requirement for topical preparation. Viscosity of FA and FB was decreased during the time of storage. The addition of atenolol concentration did not affect the viscosity significantly.

\section{AUTHORS' CONTRIBUTIONS}

The entire author equally contributed to this work.

\section{CONFLICTS OF INTEREST}

The authors have no conflicts of interest.

\section{REFERENCES}

1. Ghosh TK, Adir J, Xiang SL, Onyilofur S. Transdermal delivery of metoprolol. II: In-vitro skin permeation and bioavailability in hairless rats. J Pharm Sci 1995;84:158-60.

2. Mohammed A, et al. Transdermal Delivery of $\beta$-blockers; 2006. Available from: http://www.ingentaconnect.com.

3. Bhaskaran N, Harsha SN. Effect of permeation enhancer and iontophoresis on permeation of atenolol from transdermal gels. 2000;62:424-6.

4. Shinde UA, Modani SH, Singh KH. Design and development of repaglinide microemulsion gel for transdermal delivery. AAPS PharmSciTech 2018;19:315-25.

5. Lionberger DR, Brennan MJ. Topical nonsteroidal anti-inflammatory drugs for the treatment of pain due to soft tissue injury: Diclofenac 
epolamine topical patch. J Pain Res 2010;3:223-33.

6. Deveda P, Jian N, Khambete H, Jain S. Gellified emulsion for sustain delivery of itraconazole for topical fungal diseases. Int J Pharm Pharm Sci 2010;2:10.

7. El Laithy HM, El-Shaboury KM. The development of cutina lipogels and gel microemulsion for topical administration of fluconazole. AAPS PharmSciTech 2002;3:E35.

8. Kumar L, Verma R. In vitro evaluation of topical gel prepared using natural polymer. Int J Drug Deliv 2010;2:58-63.

9. Gennaro AR, editor. Remington: The Science and Practice of Pharmacy. $19^{\text {th }}$ ed. Easton: Mack Publishing Company; 1995.

10. Ansel HC, Allen LV Jr., Popovich NG. Pharmaceutical Dosage forms and Drug Delivery Systems. $7^{\text {th }}$ ed. New York: Lippincott Williams and Wilkins; 1999.

11. Aparna C, Srinivas KS, Patnaik R. Enhanced transdermal permeability of telmisartan by a novel nanoemulsion gel. Int J Pharm Pharm Sci 2015;7:335-42.

12. Kim J, Shin SC. Controlled release of atenolol from the ethylene-vinyl acetate matrix. Int J Pharm 2004:273:23-7.

13. Cho CW, Shin SC. Enhanced transdermal delivery of atenolol from the ethylene-vinyl acetate matrix. Int J Pharm 2004;287:67-71

14. Gupta SP, Jain SK. Development of matrix-membrane transdermal drug delivery system for atenolol. Drug Deliv 2004;11:281-6.

15. Acharya A, Kumar GB, Ahmed MG, Paudel S. A novel approach to increase the bioavailability of candesartan cilexetil by proniosomal gel formulation: In-vitro and in-vivo evaluation. Int J Pharm Pharm Sci 2016;8:413-20.

16. Souza C, de Freitas LAP, Maia Campos PMBG. Topical formulation containing beeswax-based nanoparticles improved in vivo skin barrier function. AAPS PharmSciTech 2017;18:2505-16.

17. Wagemaker TA, Silva SA, Leonardi GR. Maia campos PMBG green Coffea arabica $\mathrm{L}$. seed oil influences the stability and protective effects of topical formulations. Ind Crop Prod 2015;63:34-40.

18. Tadros T. Application of rheology for assessment and prediction of the long-term physical stability of emulsions. Adv Colloid Interface Sci 2004;108-109:227-58 